\title{
Time to Detection of Anemia and Its Predictors Among Children Receiving Antiretroviral Therapy at Debre Tabor Referral Hospital and University of Gonder Compressive Specialized Hospital, 2020: A Multicenter Retrospective Follow-Up Study
}

\section{Ermias Chanie ( $\nabla$ ermisis1888@gmail.com)}

Debre Tabor University

\section{Dejen feleke}

Debre Tabor University

Sintayehu ehu Alemayehu

Debre Tabor University

Fisha GebreEyesus

Wolkite University

\section{Aragaw Tesfaw \\ Debre Tabor University \\ Wubet Bayih \\ Debre Tabor University \\ Agimasie Tigabu \\ Debre Tabor University \\ Yared Ayinalem \\ Debre Berhan University \\ Aberham Amare \\ Debre Tabor University \\ Demeke Mesfine \\ Debre Tabor University \\ Fentaw Dagnaw \\ Debre Tabor University \\ Bruk Abate \\ Woldia University}

\section{Research Article}

Keywords: Time to detection, Anemia, Predictors, Children, ART, Ethiopia

Posted Date: January 6th, 2021

DOI: https://doi.org/10.21203/rs.3.rs-135419/v1

License: (c) This work is licensed under a Creative Commons Attribution 4.0 International License. Read Full License 
Version of Record: A version of this preprint was published at BMC Pediatrics on March 30th, 2021. See the published version at https://doi.org/10.1186/s12887-021-02616-0. 


\section{Abstract}

Background: Although antiretroviral therapy access for HIV infected children increased dramatically, anemia have been continued as a challenge regardless of cluster of differentiation (CD4) count and viral load. Hence, this study aimed to assess the time to detection of anemia and its predictors among children receiving antiretroviral therapy at Debre Tabor referral hospital and University of Gonder Compressive Specialized hospital, 2020.

Methods: A retrospective follow-up study was conducted from January 2010 to December 2018. A total of 372 children under the age of 15 who had received ART were included in the study. Data were collected from children's medical charts and ART registration logbook using a standard checklist. Besides, the data were entered into EPi data 4.2.2 and then exported to Stata 14.0 for further analysis. The Cox regression model, the variables having P-value $\leq .05$ with $95 \%$ Cls in multivariable analysis were declared as a statistically significant for anemia

Result: The mean ( \pm SD) of follow-up periods were $56.6 \pm 1.7$ SD months. The overall median survival time free from anemia was 137 months, and the incidence rate of anemia was 6.9 per 100 PYO (95\% Cl: 5.3, 7.8). Moreover, WHO clinical staging of III/IV [AHR: 4.2, 95\% Cl: 1.80, 11.1], low CD4 count below threshold [AHR: 1.9, 95\% Cl: 1.09, 3.37], cotrimoxazole preventive therapy non-users, and poor level of adherence [(AHR: $2.4,95 \%$ Cl: $1.20,4.85]$ were the main predictors of anemia.

Conclusion: The incidence rate of anemia was found to be high. Monitor hemoglobin levels routinely with concurrently CD4 cell count levels, WHO clinical stage, and level of adherence. Hence, preventing and correcting of those predictors in a systematic manner in ongoing basis is crucial. Moreover, strategies need to be strengthened cotrimoxazole preventive therapy supplementation

\section{Background}

Hematological abnormalities are a common and independent poor prognostic marker of HIV disease ${ }^{1,2}$, which worsens quality of life $^{3}$, and decreased survival ${ }^{4}$. Moreover, hematological abnormalities, mainly anemia has been continued as a challenge in resource limited setting ${ }^{5}$.

Anemia is the commonest disorder which is seen among HIV infected children ${ }^{6}$. WHO estimates that over 2 billion people are anemic worldwide, of these, more than 100 million of anemic children were living in Africa ${ }^{7}$. Even though ART access for HIV infected children increased dramatically, side effects have been continued after the initiation of therapy predominantly in resource-limited setting ${ }^{3}$. Besides, anemia has been a strong risk factor for disease progression and subsequent death regardless of cluster of differentiation (CD4) count and viral load ${ }^{4,8}$.

Hematological abnormalities have been documented as the second cause of morbidity and mortality in HIV-infected children living in resource-limited countries ${ }^{9}$. Indeed, anemia is a common ${ }^{10}$. Anemia is the leading hematologic complication of HIV infection occurring in approximately $30 \%$ of patients with asymptomatic infection and as many as $75-80 \%$ of those with Acquired immunodeficiency disease (AIDS) ${ }^{11}$, particularly in children whose immune systems are not yet fully developed ${ }^{12}$. Additionally, children are the most vulnerable population for anemia, it is responsible for a high proportion of HIV-related deaths each year ${ }^{7}$, up to $90 \%$ of children develop anemia during HIV infection ${ }^{13}$.

Anemia is a leading cause of hospital admission, reduced cognitive development, growth, and poor immune function in children ${ }^{7}$, since the etiology and pathogenesis of anemia are complex ${ }^{14}$, caused by a multifactorial of factors. such as cancer; micronutrient deficiencies; infections, such as malaria and tuberculosis(TB) ${ }^{15}$. In HIV-infected children, the virus can infect parts of the bone marrow responsible for manufacturing red blood cells and erythropoietin, which is required 
to stimulate red blood cell production ${ }^{16}$. Besides, a certain antiretroviral medication causes and exacerbates the anemia due to bone marrow suppression ${ }^{17}$.

Giving attention to the young age of children ${ }^{18}$ and children with unemployment parent ${ }^{19}$, children with viral load > 1000 copies/ml ${ }^{9,20}$, low CD4 count $<200$ cells/ul ${ }^{21,22}$, and WHO stage III/IV) ${ }^{7,20,23}$, have been recommended to reduce the impact of HIV associated anemia in the previous era.

Despite the above prevention and management approach has been implemented in Ethiopia, the burden of anemia in HIV infected children is still intolerable. Besides, it attracts the attention of the government and researchers since there has been no prior evidence about the time to detection of anemia and its predictors among HIV infected children in the country in general and in the study area in particular. Hence, this study aims to assess time to detection of anemia and its predictors among children receiving Antiretroviral Therapy at Debre Tabor referral Hospital and University of Gonder Compressive specialized Hospital.

\section{Methods}

\section{Study design and period}

A retrospective follow-up study was conducted from January1, 2009-December 30, 2018 at Debre Tabor referral Hospital and university of Gonder Compressive specialized Hospital.

\section{Study setting}

Debre Tabor referal Hospital is the largest hospital in South Gondar Zone which provide in outpatient, inpatient and operation theatre department. The Hospital has been provided service for 2.4 million populations' including ART service. Besides, University of Gondar Hospital is a 400-bed university hospital, which acts as the referral centre for four district hospitals in the area. It has a range of. The hospital services about four million across the region ${ }^{25}$.

\section{Source population}

All children < 15 years received Antiretroviral therapy at university of Gondar comprehensive specialized hospital

\section{Study population}

All children < 15 years received antiretroviral therapy from January1, 2010-December 30, 2018, at Debre Tabor referral hospital and university of Gonder Compressive specialized hospital

\section{Inclusion criteria}

All children < 15 years received Antiretroviral therapy from January1, 2010-December 30, 2018, at Debre Tabor referral hospital and university of Gonder Compressive specialized hospital

\section{Exclusion criteria}

Medical charts and ART registration logbook of the study participants with incomplete outcome (i.e. hemoglobin status not recorded) variables were excluded.

\section{Sample size and sampling Procedure}

The sample size was calculated by using Log-rank survival data analysis of the two-population proportion formula based on the following important assumptions- 95\% confidence level, $80 \%$ optimum statistical power, and taking type one error $5 \%$. By considering a study was conducted in eastern Ethiopia ${ }^{26}$, by taking sex as a predictor variable (on 
male as exposed group denoted by q1 (0.38) and female group denoted by q0 (0.53), and then the total sample size, after adding $10 \%$ as incomplete medical records, and the final sample size was 372 .

A total of 372 children who started ART during the study period were identified in the pediatric ART clinics, the investigator assigned the registration numbers from January 1, 2010, to May 30, 2020 in a chronological order. Of these, the investigator drew 357 samples which fulfilled the inclusion criteria after reviewing the medical charts and ART registration logbook; and then 15 medical records did not fulfill the inclusion criteria were excluded (Fig. 1).

\section{Variables of the study}

The dependent variable of this study is time to anemia, whereas age, sex, educational status, marital status, occupation, religion, residence, relationship to the child, ART regimen, duration of ART, level of adherence, OI prophylaxis (IP\& CPT), developmental milestone/Functional status, treatment failure, history of TB, WHO clinical stage, CD4 count/percent, nutritional status (WGT-Age, WGT-H \&HT-Age), and history of OI were independent variables.

\section{Operational definitions}

Time to anemia: - The time from children ART initiation to the occurrence of the event (i.e. anemia) during the follow-up period. Anemia was defined based on the WHO cut-off point (hemoglobin less than $10 \mathrm{~g} / \mathrm{dl}$ ) for children below 15 years 27,28 .

Censored: A study participants who were lost to follow-up, transfer to another service, and end of the study period before developing anemia were considered as censored.

\section{Data collection tools and procedures}

Data extraction tool was derived from a standard national HIV follow-up form of Ethiopia. Data were extracted from medical charts and ART registration logbook in terms of socio-demographic variables of the children and parents/caregivers. Likewise, clinical and treatment related variables were extracted from medical charts and ART registration logbook. The three nurses who are experience in ART clinic were collecting the data. Besides, the data collectors have a qualification of university degree.

\section{Data quality control}

A Pretest was conducted among 19(5\%) medical records to check the consistency of the abstraction tools from 2008, to 30, 2009 at University of Gondar comprehensive specialized hospital. Two-days training were given about the objectives, significance, and variables of the research for data collectors and supervisors. Besides, all data collectors and supervisors were taken basic ART training and mentorship. The filled formats were checked for completeness by the supervisor, data cleaning and double data entry were carried out to check for any inconsistencies, coding errors, missing values, and out of range.

\section{Data processing and analysis}

Data was entered into EPi data 4.2.2 then exported to Stata version 14 for further analysis. A categorical data was presented as frequency and continuous data as median and interquartile range (IQR). The incidence rate of anemia was calculated with children with anemia as the numerator divided by total child-months. The cumulative probability of anemia was estimated using Kaplan-Meier failure method and the survival curves were compared between the predictor variable by the log-rank test. In Cox regression analysis, variables having a $p$ - value $\leq 0.25$ were enter into multivariable and the variables having $\leq .05$ in multivariable were declared as a statistically significant for anemia. Besides, the model and the variable were tested via graphic and numerical assessment (global test $=0.644$ ). 


\section{Results}

\section{Socio-demographic characteristics}

Out of 372 records, 357 of pediatric ART records with the completeness response rate of $95.9 \%$ were reviewed and 15 of the medical records were excluded from study. The median age of children and caregivers were 7.3(SD+-0.28) and 34.9 (SD +-0.37) years respectively. More than half the children 184(51.5\%) were male, whereas $193(54.1 \%)$ caregivers were female. About $285(79.8 \%)$ of the caregiver's were urban residences and $249(69.7 \%)$ were married. Majority of the caregivers 302(84.6\%) were orthodox Christian; likewise, 330 were Amara ethnic group. Moreover, 147(41.2\%) and $193(54.1 \%)$ of the caregivers were uneducated and unemployed respectively, and $203(56.9 \%)$ of the children were enrolled before test and treat strategies (Table 1). 
Table 1

Socio demographic characteristics among children receiving Antiretroviral Therapy at Debre

Tabor referral Hospital and university of Gonder Compressive Specialized Hospital, 2020

$(n=357)$

\begin{tabular}{|c|c|c|c|}
\hline Exposure variable & Responses & Frequency $(n=202)$ & Percent (\%) \\
\hline \multirow[t]{2}{*}{ Age of the Caregiver's } & $\leq 34$ years & 216 & 60.5 \\
\hline & $>34$ years & 141 & 39.5 \\
\hline \multirow[t]{2}{*}{ Sex Caregiver's } & Male & 164 & 45.9 \\
\hline & Female & 193 & 54.1 \\
\hline \multirow[t]{2}{*}{ Age of the child (years) } & $\leq 7$ & 178 & 49.9 \\
\hline & $>7$ & 179 & 50.1 \\
\hline \multirow[t]{2}{*}{ Sex } & Male & 184 & 51.5 \\
\hline & Female & 173 & 48.5 \\
\hline \multirow[t]{2}{*}{ Residence } & Rural & 72 & 20.2 \\
\hline & Urban & 285 & 79.8 \\
\hline \multirow[t]{3}{*}{ Caregiver's Marital status } & Married & 249 & 69.7 \\
\hline & Widowed & 37 & 10.4 \\
\hline & Divorced & 71 & 19.9 \\
\hline \multirow[t]{3}{*}{ Ethnicity } & Amhara & 338 & 94.7 \\
\hline & Tigray & 17 & 4.8 \\
\hline & Others & 2 & 0.6 \\
\hline \multirow[t]{3}{*}{ Religion } & Orthodox & 302 & 84.6 \\
\hline & Muslim & 49 & 13.7 \\
\hline & Other* & 6 & 1.7 \\
\hline \multirow[t]{4}{*}{ Caregiver's educational status } & No education & 147 & 41.2 \\
\hline & Primary education & 92 & 25.8 \\
\hline & Secondary education & 96 & 26.9 \\
\hline & Tertiary education & 22 & 6.2 \\
\hline \multirow[t]{2}{*}{ Caregiver's Occupation } & Non employed & 193 & 54.1 \\
\hline & Employed & 164 & 45.9 \\
\hline
\end{tabular}

\section{Clinical and treatment related characteristics}

A total of $70(19.6 \%)$ and $111(31.1 \%)$ of children were CD4 counted below the threshold level and WHO clinical III and IV respectively. Besides, $41(11.5 \%)$ had tuberculosis and 181 (50.7\%) had a history of opportunistic infection in the followup period. The majority $309(86.6 \%)$ of children were zidovudine regimen contain, and $291(81.5 \%)$ had taken Cotrimoxazole preventive therapy. whereas, only 109(30.5\%) had taken isoniazid preventive therapy. Regarding to 
nutritional status, $182(59.1 \%)$ and $146(40.9 \%)$ of the children were underweight and stunted respectively. 36(10.15) of the children had treatment failure, and 199(55.7\%) of the children were $<60$ months on ART (Table 2).

Table 2

Clinical and treatment related characteristics among children receiving Antiretroviral Therapy at Debre Tabor referral Hospital and university of Gonder Compressive Specialized Hospital, $2020(n=357)$

\begin{tabular}{|c|c|c|c|}
\hline Exposure variable & Responses & Frequency $(n=202)$ & Percent (\%) \\
\hline \multirow[t]{2}{*}{ Weight for height } & Normal & 175 & 49.0 \\
\hline & Underweight & 182 & 59.1 \\
\hline \multirow[t]{2}{*}{ Height for age } & Normal & 211 & 59.1 \\
\hline & Stunted & 146 & 40.9 \\
\hline \multirow[t]{2}{*}{ CD 4 counts or $\%$} & Below threshold & 70 & 19.6 \\
\hline & Above threshold & 287 & 80.4 \\
\hline \multirow[t]{2}{*}{ WHO stages } & Stage I\&II & 244 & 68.3 \\
\hline & Stage III\&IV & 111 & 31.1 \\
\hline \multirow[t]{2}{*}{$\mathrm{Hx}$ of Ols } & Yes & 181 & 50.7 \\
\hline & No & 176 & 49.3 \\
\hline \multirow[t]{2}{*}{ Regimen at baseline } & AZT-based & 309 & 86.6 \\
\hline & d4T-based & 48 & 13.4 \\
\hline \multirow{2}{*}{$\begin{array}{l}\text { Cotrimoxazole } \\
\text { preventive therapy (CPT) }\end{array}$} & Yes & 291 & 81.5 \\
\hline & No & 66 & 18.5 \\
\hline \multirow[t]{2}{*}{ Isoniazid preventive therapy (IPT) } & Yes & 109 & 30.5 \\
\hline & No & 248 & 69.5 \\
\hline \multirow[t]{3}{*}{ ART adherence } & Good & 278 & 77.9 \\
\hline & Fair & 31 & 8.7 \\
\hline & Poor & 48 & 13.4 \\
\hline \multirow[t]{2}{*}{ Treatment failure } & Yes & 36 & 10.1 \\
\hline & No & 321 & 89.9 \\
\hline \multirow[t]{2}{*}{ TB status } & Yes & 41 & 11.5 \\
\hline & No & 316 & 88.5 \\
\hline \multirow[t]{2}{*}{ HAART duration } & $<=5$ years & 199 & 55.7 \\
\hline & $>5$ years & 158 & 44.3 \\
\hline \multirow[t]{2}{*}{ Follow-up status Anemia } & Yes & 58 & 16.2 \\
\hline & No & 299 & 83.8 \\
\hline
\end{tabular}




\section{The median survival time to develop anemia during follow-up period}

The mean follows-up periods were $56.6 \pm 1.7$ SD months, overall yielding 20,191 child-month observations. At the end of follow-up, $58[16.5 \%, 95 \% \mathrm{Cl}: 12.8-20.4 \%]$ of the children were anemia while $299(83.8 \%)$ of children were nonanemic. The incidence rate of anemia was 6.9 per 100 PYO (95\% Cl: $5.3,7.8)$. The overall median survival time of children free from anemia was 137 months (Fig. 2). The median survival time free from anemia among children who had CD 4 count below the threshold level were 62 months, while 125 who had CD4 count above the threshold level. Besides, 70 months among children who had WHO stage III and IV, and 107 months for those WHO stage I and II to develop anemia in the follow-up period. The median survival time free from anemia among children who had who had zidovudine regimen were 60 months, while 140 months for those non-zidovudine regimens contained to in the followup period (Fig. 3). Log rank survival curve comparisons of the associated predictor's variables were estimated. Besides, Cox-Snell residual Nelson- Alen cumulative hazard graph for the goodness of model fitness also evaluated (Fig. 4).

In Cox proportional hazard model bivariable analysis including sex of caregivers, occupation of caregivers, test and treat strategies, weight for age, height for age, TB status, regimen type, CPT, CD4 count threshold level, level of adherence, $\mathrm{WHO}$ clinical staging and $\mathrm{OI}$ status were having $\mathrm{P}$ value less than 0.25 for the occurrence of anemia and enter into multivariable analysis. Besides, in multivariable models, test and treat strategies, WHO clinical staging, CD4 count threshold level, CPT, and level of adherence were associated with anemia.

The hazards of anemia in children enrolled before test and treat strategies (Pre ART) were 2.0 times higher than those after test and treat strategy [AHR: 2.0(95\% Cl: 1.13, 3.57)]. The hazard of anemia in children who had WHO staging III and IV were increased a risk of anemia by 4.2 times as compared with WHO staging I and II [AHR: 4.2 (95\% Cl: 1.80, 11.1)]. Besides, Children who had CD4 count below the threshold level were increased a risk of anemia by 1.9 times as compared with CD4 count above the threshold level [AHR: 1.9 (95\% Cl: 1.09, 3.37)]. Moreover, children who had cotrimoxazole preventive therapy non-users were 2.2 times higher than those who those cotrimoxazole preventive therapy users [AHR: $2.2(95 \% \mathrm{Cl}: 1.23,3.82)$ ], and children with poor level of adherence were increased a risk of anemia by 2.4 times [(AHR: 2.4 (95\% Cl: 1.20,4.85)] (Table 3). 
Table 3

Bivariable and multivariable Cox-regression analysis of predictors for anemia among children receiving Antiretroviral Therapy at Debre Tabor referral Hospital and university of Gonder Compressive Specialized Hospital, $2020(n=357)$

\begin{tabular}{|c|c|c|c|c|c|c|}
\hline \multirow[t]{2}{*}{ Characteristics } & & \multicolumn{2}{|c|}{ Anemic } & \multicolumn{3}{|l|}{ OR $(95 \% \mathrm{Cl})$} \\
\hline & & $\begin{array}{l}\text { Yes } \\
\text { (58) }\end{array}$ & $\begin{array}{l}\text { No } \\
(299)\end{array}$ & COR & AOR & $\begin{array}{l}\text { P- } \\
\text { value }\end{array}$ \\
\hline \multirow[t]{2}{*}{ Age of the Caregiver's } & $\leq 34$ years & 34 & 182 & $\begin{array}{l}0.9(0.55- \\
1.57)\end{array}$ & - & \\
\hline & $>34$ years & 24 & 117 & Ref & - & \\
\hline \multirow[t]{2}{*}{ Sex Caregiver's } & Male & 30 & 134 & $\begin{array}{l}1.4(0.83- \\
2.32)\end{array}$ & $\begin{array}{l}1.3(0.82- \\
2.38)\end{array}$ & 0.220 \\
\hline & Female & 28 & 165 & Ref & Ref & \\
\hline \multirow[t]{2}{*}{ Age of the child (years) } & $\leq 7$ & 25 & 153 & $\begin{array}{l}0.8(0.45- \\
1.28)\end{array}$ & - & \\
\hline & $>7$ & 33 & 146 & Ref & - & \\
\hline \multirow[t]{2}{*}{ Sex } & Male & 29 & 155 & $\begin{array}{l}1.0(0.59- \\
1.66)\end{array}$ & - & \\
\hline & Female & 29 & 144 & Ref & - & \\
\hline \multirow[t]{2}{*}{ Residence } & Rural & 10 & 62 & $\begin{array}{l}0.8(0.45- \\
1.75)\end{array}$ & - & \\
\hline & Urban & 48 & 237 & Ref & - & \\
\hline \multirow[t]{3}{*}{ Marital status } & Married & 39 & 210 & $\begin{array}{l}0.9(0.49- \\
1.70)\end{array}$ & - & \\
\hline & Divorced & 5 & 32 & $\begin{array}{l}0.7(0.27- \\
2.09)\end{array}$ & - & \\
\hline & Widowed & 14 & 57 & $\begin{array}{l}0.8(0.34- \\
2.41)\end{array}$ & - & \\
\hline \multirow[t]{3}{*}{ Religion } & Orthodox & 49 & 253 & $\begin{array}{l}1.4(0.18- \\
10.8)\end{array}$ & - & \\
\hline & Muslim & 8 & 41 & $\begin{array}{l}1.3(0.16- \\
11.3)\end{array}$ & - & \\
\hline & Other* & 1 & 5 & Ref & - & \\
\hline \multirow[t]{4}{*}{$\begin{array}{l}\text { Caregiver's educational } \\
\text { status }\end{array}$} & No education & 25 & 122 & $\begin{array}{l}0.7(0.28- \\
1.89)\end{array}$ & - & \\
\hline & Primary education & 15 & 77 & $\begin{array}{l}0.6(0.23- \\
1.77)\end{array}$ & - & \\
\hline & $\begin{array}{l}\text { Secondary } \\
\text { education }\end{array}$ & 13 & 83 & $\begin{array}{l}0.6(0.20- \\
1.55)\end{array}$ & - & \\
\hline & Tertiary education & 5 & 17 & Ref & - & \\
\hline
\end{tabular}




\begin{tabular}{|llllll|}
\hline Occupation of the caregiver & Non employed & 37 & 156 & $\begin{array}{l}1.6(0.94- \\
2.76)\end{array}$ & $\begin{array}{l}2.1(0.97- \\
3.89)\end{array}$ \\
\cline { 2 - 6 } & Employed & 21 & 143 & Ref & Ref \\
\hline$b$ & & & & & \\
\hline
\end{tabular}


Table 3

(continued): Bivariable and multivariable Cox-regression of predictor variable

\begin{tabular}{|c|c|c|c|c|c|c|}
\hline \multirow[t]{2}{*}{ Characteristics } & & \multicolumn{2}{|c|}{ Anemic } & \multicolumn{3}{|c|}{ OR $(95 \% \mathrm{Cl})$} \\
\hline & & $\begin{array}{l}\text { Yes } \\
(58)\end{array}$ & $\begin{array}{l}\text { No } \\
(299)\end{array}$ & COR & AOR & P-value \\
\hline \multirow[t]{2}{*}{ Weight for height } & Normal & 21 & 154 & Ref & Ref & \\
\hline & Underweight & 37 & 145 & $\begin{array}{l}1.9(1.10- \\
3.24)\end{array}$ & $\begin{array}{l}1.5(0.88- \\
2.72)\end{array}$ & 0.127 \\
\hline \multirow[t]{2}{*}{ Height for age } & Normal & 28 & 183 & Ref & Ref & \\
\hline & Stunted & 30 & 116 & $\begin{array}{l}1.5(0.92- \\
2.59)\end{array}$ & $\begin{array}{l}1.2(0.69- \\
2.05)\end{array}$ & 0.543 \\
\hline \multirow[t]{2}{*}{ CD4 counts or $\%$} & Below threshold & 21 & 49 & $\begin{array}{l}2.4(1.39- \\
4.09)\end{array}$ & $\begin{array}{l}1.9(1.09- \\
3.37)\end{array}$ & 0.024 \\
\hline & Above threshold & 37 & 250 & Ref & Ref & \\
\hline \multirow[t]{2}{*}{ WHO stages } & Stage I\&II & 24 & 220 & Ref & & \\
\hline & Stage III\&IV & 34 & 77 & $\begin{array}{l}4.3(2.50- \\
7.24)\end{array}$ & $\begin{array}{l}4.2(1.8- \\
11.1)\end{array}$ & $0.001^{\star *}$ \\
\hline \multirow{2}{*}{$\begin{array}{l}\text { Hx of opportunistic } \\
\text { infections }\end{array}$} & No & 17 & 159 & Ref & Ref & \\
\hline & Yes & 41 & 140 & $\begin{array}{l}2.7(1.56- \\
4.85)\end{array}$ & $\begin{array}{l}1.1(0.45- \\
2.85)\end{array}$ & 0.800 \\
\hline \multirow[t]{2}{*}{ Regimen at baseline } & AZT-based & 52 & 257 & $\begin{array}{l}1.4(0.60- \\
3.24)\end{array}$ & - & \\
\hline & d4T-based & 6 & 42 & Ref & - & \\
\hline \multirow{2}{*}{$\begin{array}{l}\text { Cotrimoxazole } \\
\text { preventive therapy (CPT) }\end{array}$} & No & 22 & 44 & $\begin{array}{l}3.1(1.82- \\
5.32)\end{array}$ & $\begin{array}{l}2.2(1.23- \\
3.82)\end{array}$ & $0.008^{\star *}$ \\
\hline & Yes & 36 & 255 & Ref & Ref & \\
\hline \multirow[t]{2}{*}{$\begin{array}{l}\text { Isoniazid preventive } \\
\text { therapy (IPT) }\end{array}$} & No & 40 & 208 & $\begin{array}{l}1.0(0.55- \\
1.72)\end{array}$ & - & \\
\hline & Yes & 18 & 91 & Ref & - & \\
\hline \multirow[t]{3}{*}{ ART adherence } & Good & 39 & 241 & Ref & Ref & \\
\hline & Fair & 9 & 22 & $\begin{array}{l}4.3(2.02- \\
8.98)\end{array}$ & $\begin{array}{l}2.0(0.88- \\
4.79)\end{array}$ & 0.094 \\
\hline & Poor & 12 & 36 & $\begin{array}{l}2.8(1.45- \\
5.37)\end{array}$ & $\begin{array}{l}2.4(1.20- \\
4.85)\end{array}$ & $0.016 *$ \\
\hline \multirow[t]{2}{*}{ Treatment failure } & Yes & 5 & 31 & $\begin{array}{l}1.0(0.38- \\
2.42)\end{array}$ & - & \\
\hline & No & 53 & 268 & Ref & - & \\
\hline \multirow[t]{2}{*}{ TB status } & Yes & 11 & 30 & $\begin{array}{l}2.6(1.34- \\
5.00)\end{array}$ & $\begin{array}{l}0.7(0.32- \\
1.53)\end{array}$ & 0.369 \\
\hline & No & 47 & 269 & Ref & Ref & \\
\hline
\end{tabular}




\begin{tabular}{|c|c|c|c|c|c|c|}
\hline \multirow[t]{2}{*}{ Duration on ART } & $<=5$ years & 43 & 156 & $1.2(0-3-3.2)$ & - & \\
\hline & $>5$ years & 15 & 143 & Ref & - & \\
\hline \multirow[t]{2}{*}{ ART initiation } & after test and treat & 20 & 134 & Ref & Ref & \\
\hline & $\begin{array}{l}\text { before test and } \\
\text { treat(pre-ART) }\end{array}$ & 38 & 165 & $\begin{array}{l}1.5(0.89- \\
2.62)\end{array}$ & $\begin{array}{l}2.0(1.13- \\
3.57)\end{array}$ & $0.017^{*}$ \\
\hline
\end{tabular}

*Significant at <0.05; ** Significant at <0.01; COR = Crude odds ratio; $A O R=$ adjusted odds ratio; Ref = reference category; $\mathrm{Cl}=$ confidence interval

\section{Discussion}

This study assessed the time to detection of anemia and its predictors among time to detection of anemia and its predictors among children receiving Antiretroviral Therapy at Debre Tabor referral Hospital and university of Gonder Compressive Specialized Hospital, Ethiopia, Northwest, Ethiopia; 2020. Almost one-in-six HIV infected children (16.5\%, $\mathrm{n}=58$ ) with anemia were recorded in the follow-up period. The incidence rate of anemia was 6.9 per 100 child-years. Moreover, the median survival time was 137 months. WHO clinical staging III/IV, CD4 count below the threshold level, CPT non-user, poor adherence, and before test and treat strategies (pre-ART) were found to be the main predictors of anemia.

Our finding is comparable with a cohort study conducted in northwest Ethiopia in 2012 and 2017, were 19.8\% and $12.26 \%$ respectively ${ }^{27,28}$. Moreover, a cross sectional study in Addis Ababa, Ethiopia in 2016 was $17.59 \%{ }^{29}$. This could be justified in two ways. Firstly, cut-off value of $\mathrm{Hgb}$ to define anemia. Secondly, study participants having similar age group (i.e.., children < 15 years). In addition to this, it may be due the data extraction tools of all studies were prepared from a standard HIV/AIDS Care and treatment guidelines ART service in Ethiopia.

However, this study showed a lower incidence rate of anemia than a cross sectional and prospective cohort in India were $21.9 \%^{30}$ and $47.1 \%^{31}$ respectively. In Jimma, Ethiopia in 2007, was $21.9 \%^{30}$, in Nigeria among aged between 5 and 12 years, was $54.2 \%^{32}$, in Cameron from November 2012 to May 2013 , was $49.6 \%{ }^{12}$, in South Africa, was $73 \%{ }^{33}$, in Gahan 2091 among under Five Years, was 53.8\% ${ }^{34}$, Malawi, was 45.7\% ${ }^{9}$, in Mozambique among 6-59 months of children, was $88 \%{ }^{7}$, in Kenya 2008, was $35.9 \%^{23}$, and in Tanzania in 2015 , was $27.7 \%$ respectively ${ }^{19}$. This difference could be due to the cut-off point of anemia, study design since most of the above studies were cross sectional, whereas our study was a cohort. In addition, the variations might be due to the difference in the study area, duration of time on ART, and differences in the follow-up periods. A shorter follow-up period is likely to find a higher probability of anemia when compared with a study with a longer follow-up period. Besides, the discrepancy may be due to monitoring of anemia in every three months in our study area whereas frequently in others settings. Likewise, the discrepancy may be due to the study participants (i.e. aged b/n 5-12 years and under five years).

On the other hand, the incidence rate of anemia has been observed in this study is higher than a study conducted in Hawassa Ethiopia, in 2018, which was $11.4 \%{ }^{35}$. In Asia-Pacific region, between January 2003 and September 2013, severe anemia was $5.5 \% 36$, a study conducted from November 2007 to June 2009 in the region of Africa, $4.8 \%$ of children with severe anemia ${ }^{20}$ in 2016 Uganda, Anemia was $11.8 \%$ among 12-14 years respectively ${ }^{37}$. This difference could be explained by the differences in the outcome measurement, ethnicity, sample size, study design, and follow up period. Moreover, the heterogeneity of the data inherent in a multinational cohort, the type's health care service and study setting. 
Children who were WHO clinical staging III and IV increased a risk of anemia by 4.2 times as compared with WHO clinical staging I and II. The median duration of free from anemia was significantly shorter in persons with WHO clinical staging III and IV in follow-up period. The finding is in line with a study from Mozambique, west Africa, and Kenya

$7,20,23$. This might be due to having advanced WHO clinical staging might compromise immunity, and can lead to severe illness due to viral replication, depletion of CD4 count, and the added burden of disease. Moreover, children who had CD4 count below the threshold level were increased a risk of anemia by 1.9 times as compared with CD4 count above the threshold level. Besides, the median survival time of free from anemia was significantly longer time in persons with CD4 count above the threshold level. This finding was also supported by several studies conducted in Asia, Malawi, and Nigeria ${ }^{3,9,32}$. Moreover, the finding was also similar in a study conducted in Black Lion and Zewuidtu referral hospital in Ethiopia $<350$ cells/ $\mu \mathrm{l}^{21,22}$. This could be explained by low CD4 count elicited dysfunction of the immune system and increased vulnerability of the host to infection, immunological deficiency that enhances the severity of the disease, and delayed recovery time and increase viral load across time.

Children who were CPT non-users increased the risk 2.2 times higher than those who had those CPT users. A study conducted in Ethiopia revealed that CPT non-users anemia as an independent predictor of anemia ${ }^{38}$. Moreover, the median survival time of free from anemia was significantly shorter in persons with CPT non-users. Indeed, CPT can prevent or reduce the occurrence of opportunistic infection and further complication, therefore, it is important to increase the immune status of the children to decrease viral replication which increases their survival rate by preventing and treating $\mathrm{Ol}$ infection of which is supported, by a study conducted northwest Ethiopia ${ }^{24}$. CPT prophylaxis has been recommended for the benefit of HIV/AIDS-infected individuals to prevent opportunistic infection since it is a simple and effective intervention to reduce morbidity, and to improve the quality ${ }^{39}$. Besides, children presenting with poor level of adherence was increased a risk of anemia by 2.4 times as compared with good level of adherence. Furthermore, the median of survival time to develop anemia was significantly longer time in persons with good level of adherence. This could be explained poor level of adherence has been shown to influence the natural history of HIV disease by accelerating the rate of disease progression, opportunistic infection, and mortality. Moreover, counseling about the importance of adherence has been provided in ART service to prevent opportunistic infection since it is a simple and effective intervention.

This study has some limitations. First, data were collected from routine medical care records and there were limited data on possible predictors of anemia, such as viral load level and psychological support. Second, age, educational, and occupation status of the care givers, as the presence of these variables might be causal for the occurrence of anemia during the initiation of ART.

\section{Conclusion}

The incidence rate of anemia was found to be high. Monitor hemoglobin levels routinely with concurrently CD4 cell count levels, WHO clinical stage, and level of adherence. Hence, preventing and correcting of those predictors in a systematic manner in ongoing basis is crucial. Moreover, strategies need to be strengthened cotrimoxazole preventive therapy supplementation

\section{Declarations}

\section{Ethics approval and consent to participate:}

Ethical clearance was obtained from Debre Tabor University ethical review Committee and permission letter was also obtained from each hospital administrators. Besides, Verbal informed consent was obtained from all the child's

Page $14 / 21$ 
caregiver before data collection and the principles expressed in the Declaration of Helsinki and the Good Clinical Practices.

\section{Consent for publication: Not applicable}

Availability of data and materials: Data will be had upon request from the corresponding author

Competing interests: The authors have no competing interests to declare

Funding: This research didn't receive profit

Authors' contributions: All authors have read and approved the final article. ESC contributed to conception, study design, data acquisition, data interpretation, and writing original article. GL contributed to conception and design, data acquisition, critically revising article. GA contributed to data acquisition, critically revised this article. BB contributed to conception and design, data acquisition, statistical analysis, ATD contributed to data acquisition, critically revised this article. SAA contributed to data acquisition, critically revised this article. WAB contributed to data acquisition, critically revised this article. BB contributed to data acquisition, critically revising article, and data interpretation.

Acknowledgments: We would like to express our deepest gratitude and appreciation to University of Gondar Comprehensive specialized Hospital and Debre Tabor referral Hospital administrators. Likewise, our heartfelt also goes to all individuals who participated in the study, notably ART focal person of the hospitals, and data collectors.

\section{References}

1. Beletew, B., Mengesha, A., Ahmed, M., Fitwi, A. \& Wudu, M. Determinants of Anemia among HIV-Positive Children on Highly Active Antiretroviral Therapy Attending Hospitals of North Wollo Zone, Amhara Region, Ethiopia, 2019: A Case-Control Study. Anemia 2020, (2020).

2. Belperio, P. S. \& Rhew, D. C. Prevalence and outcomes of anemia in individuals with human immunodeficiency virus: a systematic review of the literature. Am. J. Med. 116, 27-43 (2004).

3. Bunupuradah, T. et al. Incidence and predictors of severe anemia in Asian HIV-infected children using first-line antiretroviral therapy. Int. J. Infect. Dis. 17, e806-e810 (2013).

4. Moore, R. D., Keruly, J. C. \& Chaisson, R. E. Anemia and Survival in HIV Infection. JAIDS J. Acquir. Immune Defic. Syndr. 19, 29-33 (1998).

5. (PDF) Anaemia in Developing Countries: Burden and Prospects of Prevention and Control. ResearchGate https://www.researchgate.net/publication/221926480_Anaemia_in_Developing_Countries_Burden_and_Prospects_ of_Prevention_and_Control doi:http://dx.doi.org/10.5772/29148.

6. Akalu, T. Y. Anemia and Determinants among Severely Malnourished Children Admitted to Amhara Regional Referral Hospitals, Northwest Ethiopia. 2, 6 (2020).

7. Duffy, C. et al. Multiple Concurrent Illnesses Associated with Anemia in HIV-Infected and HIV-Exposed Uninfected Children Aged 6-59 Months, Hospitalized in Mozambique. Am. J. Trop. Med. Hyg. 102, 605-612 (2020).

8. Volberding, P. A. et al. Anemia in HIV infection: clinical impact and evidence-based management strategies. Clin. Infect. Dis. Off. Publ. Infect. Dis. Soc. Am. 38, 1454-1463 (2004).

9. Huibers, M. H. W. et al. Severe anaemia complicating HIV in Malawi; Multiple co-existing aetiologies are associated with high mortality. PLOS ONE 15, (2020).

10. Quaye, W. \& Addai-Mensah, A. N. Prevalence of anaemia and immunological markers among Ghanaian HAARTnaïve HIV-patients and those on HAART. Afr. Health Sci. 11, (2011).

Page 15/21 
11. Am, L. et al. Prevalence and correlates of anemia in a large cohort of HIV-infected women: Women's Interagency HIV Study. J. Acquir. Immune Defic. Syndr. 1999 26, 28-35 (2001).

12. Bate, A. et al. Malaria infection and anaemia in HIV-infected children in Mutengene, Southwest Cameroon: a cross sectional study. BMC Infect. Dis. 16, (2016).

13. Enawgaw, B. et al. Prevalence and associated risk factors of anemia among HIV infected children attending Gondar university hospital, Northwest Ethiopia: a cross sectional study. BMC Hematol. 15, 12 (2015).

14. Duedu, K. O., Sagoe, K. W. C., Ayeh-Kumi, P. F., Affrim, R. B. \& Adiku, T. The effects of co-infection with human parvovirus B19 and Plasmodium falciparum on type and degree of anaemia in Ghanaian children. Asian Pac. J. Trop. Biomed. 3, 129-139 (2013).

15. Kothari, M. T. et al. Exploring associations between water, sanitation, and anemia through 47 nationally representative demographic and health surveys. Ann. N. Y. Acad. Sci. 1450, 249-267 (2019).

16. Molaghan, J. B., N.P., A.C.R.N.Nov. 1 \& 1999. The Facts About HIV-Related Anemia. https://www.thebody.com/article/facts-hiv-related-anemia.

17. Makubi, A. et al. Burden and Determinants of Severe Anemia among HIV-Infected Adults: Results from a Large Urban HIV Program in Tanzania, East Africa. J. Int. Assoc. Provid. AIDS Care JIAPAC 14, 148-155 (2015).

18. Geletaw, T., Tadesse, M. Z. \& Demisse, A. G. Hematologic abnormalities and associated factors among HIV infected children pre- and post-antiretroviral treatment, North West Ethiopia. J. Blood Med. 8, 99-105 (2017).

19. Simbauranga, R. H., Kamugisha, E., Hokororo, A., Kidenya, B. R. \& Makani, J. Prevalence and factors associated with severe anaemia amongst under-five children hospitalized at Bugando Medical Centre, Mwanza, Tanzania. BMC Hematol. 15, (2015).

20. Nyesigire Ruhinda, E., Bajunirwe, F. \& Kiwanuka, J. Anaemia in HIV-infected children: severity, types and effect on response to HAART. BMC Pediatr. 12, 170 (2012).

21. Mengist, H. M., Taye, B. \& Tsegaye, A. Intestinal Parasitosis in Relation to CD4 + T Cells Levels and Anemia among HAART Initiated and HAART Naive Pediatric HIV Patients in a Model ART Center in Addis Ababa, Ethiopia. PLoS ONE 10, (2015).

22. Mihiretie, H., Taye, B. \& Tsegaye, A. Magnitude of Anemia and Associated Factors among Pediatric HIV/AIDS Patients Attending Zewditu Memorial Hospital ART Clinic, Addis Ababa, Ethiopia. Anemia vol. 2015 e479329 https://www.hindawi.com/journals/anemia/2015/479329/ (2015).

23. Kibaru, E. G., Nduati, R., Wamalwa, D. \& Kariuki, N. Impact of highly active antiretroviral therapy on hematological indices among HIV-1 infected children at Kenyatta National Hospital-Kenya: retrospective study. AIDS Res. Ther. 12, 26 (2015).

24. Atalell, K. A., Birhan Tebeje, N. \& Ekubagewargies, D. T. Survival and predictors of mortality among children coinfected with tuberculosis and human immunodeficiency virus at University of Gondar Comprehensive Specialized Hospital, Northwest Ethiopia. A retrospective follow-up study. PloS One 13, e0197145 (2018).

25. WHOI Gondar, Ethiopia - Leicester, England. WHO http://www.who.int/patientsafety/implementation/apps/first_wave/ethiopia_leicester/en/?

26. Teklemariam, Z., Mitiku, H. \& Mesfin, F. Prevalence of anemia and nutritional status among HIV-positive children receiving antiretroviral therapy in Harar, eastern Ethiopa. HIV/AIDS - Research and Palliative Care vol. 7 191-196 https://www.dovepress.com/prevalence-of-anemia-and-nutritional-status-among-hiv-positive-childre-peer-reviewedfulltext-article-HIV (2015).

27. Koye, D. N., Ayele, T. A. \& Zeleke, B. M. Predictors of mortality among children on Antiretroviral Therapy at a referral hospital, Northwest Ethiopia: a retrospective follow up study. BMC Pediatr. 12, 161 (2012). 
28. Wagnew, F. et al. Burden of anemia and its association with HAART in HIV infected children in Ethiopia: a systematic review and meta-analysis. BMC Infect. Dis. 19, 1-9 (2019).

29. Enawgaw, B. et al. Prevalence and associated risk factors of anemia among HIV infected children attending Gondar university hospital, Northwest Ethiopia: a cross sectional study. BMC Hematol. 15, (2015).

30. Abebe, M. \& Alemseged, F. Hematologic abormalities among children on Haart, in Jimma University Specialized Hospital, Southwestern ethiopia. Ethiop. J. Health Sci. 19, (2009).

31. Shet, A. et al. Anemia, diet and therapeutic iron among children living with HIV: a prospective cohort study. BMC Pediatr. 15, (2015).

32. Ahumareze, R. E. et al. Prevalence of Anaemia and the Relationship between Haemoglobin Concentration and CD4 Count in HIV Positive Children on Highly Active Antiretroviral Therapy (HAART) in Lagos, Nigeria. Curr. Pediatr. Res. 20, (2016).

33. Eley, B. S., Sive, A. A., Shuttleworth, M. \& Hussey, G. D. A prospective, cross-sectional study of anaemia and peripheral iron status in antiretroviral naïve, HIV-1 infected children in Cape Town, South Africa. BMC Infect. Dis. 2, 3 (2002).

34. Parbey, P. A. et al. Risk Factors of Anaemia among Children under Five Years in the Hohoe Municipality, Ghana: A Case Control Study. Anemia 2019, (2019).

35. Fenta, D. A., Nuru, M. M., Yemane, T., Asres, Y. \& Wube, T. B. Anemia and Related Factors Among Highly Active Antiretroviral Therapy Experienced Children in Hawassa Comprehensive Specialized Hospital, Southern Ethiopia: Emphasis on Patient Management. Drug Healthc. Patient Saf. 12, 49-56 (2020).

36. Lumbiganon, P. et al. HIV-infected children in the Asia-Pacific region with baseline severe anemia: antiretroviral therapy and outcomes. Asian Biomed. 10, 229-234 (2017).

37. Id, L., A, A., R, S., P, O.-O. \& Jb, B. Prevalence of Anaemia and Associated Risk Factors among Children in Northwestern Uganda: A Cross Sectional Study. BMC Hematol. 17, 10-10 (2017).

38. Enawgaw, B. et al. Prevalence and associated risk factors of anemia among HIV infected children attending Gondar university hospital, Northwest Ethiopia: a cross sectional study. BMC Hematol. 15, 12 (2015).

39. Date, A. A. et al. Implementation of co-trimoxazole prophylaxis and isoniazid preventive therapy for people living with HIV. Bull. World Health Organ. 88, 253-259 (2010).

\section{Figures}




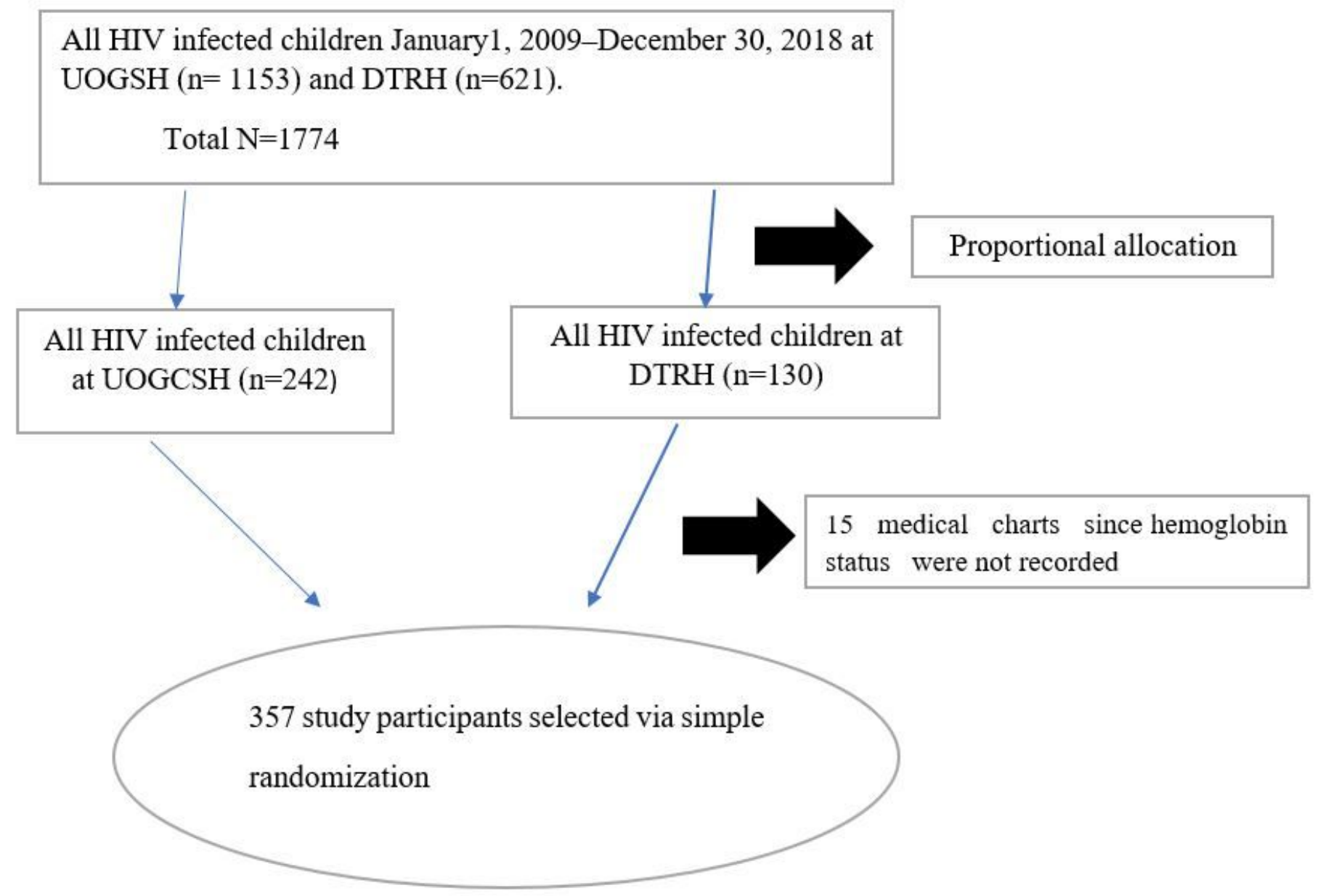

Figure 1

Diagrammatic presentation of sampling procedure among children received Antiretroviral Therapy at Debre Tabor Referral Hospital and University of Gonder Compressive Specialized Hospital, Northwest, Ethiopia 2020 (n=357) Key: DTRH=Debre Tabor Referral Hospital, UOGCSH= University of Gonder Compressive Specialized Hospital 


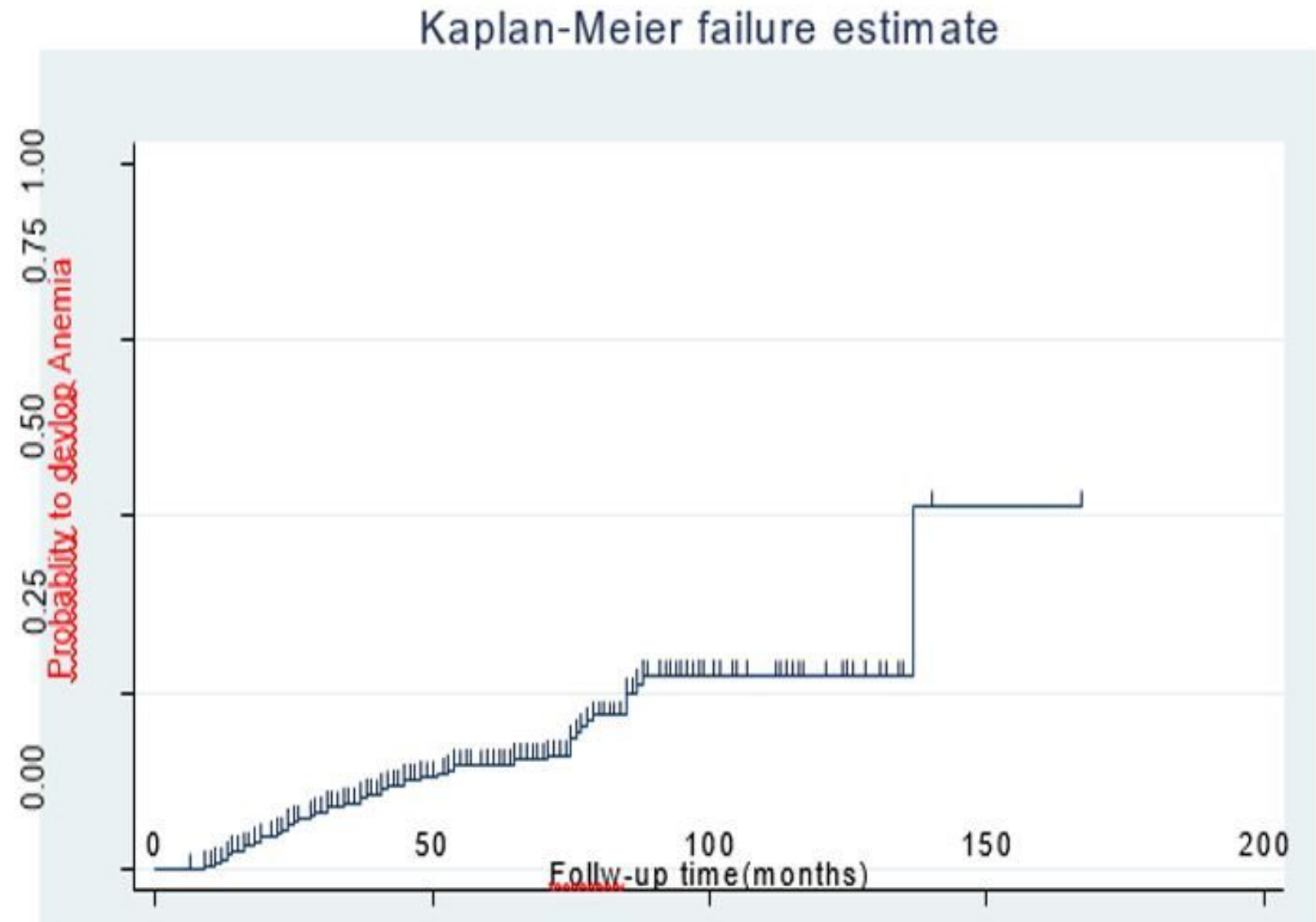

\section{Figure 2}

Kaplan-Meier failure estimate of anemia among children received Antiretroviral Therapy at Debre Tabor Referral Hospital and University of Gonder Compressive Specialized Hospital, Northwest, Ethiopia 2020 (n=357) 

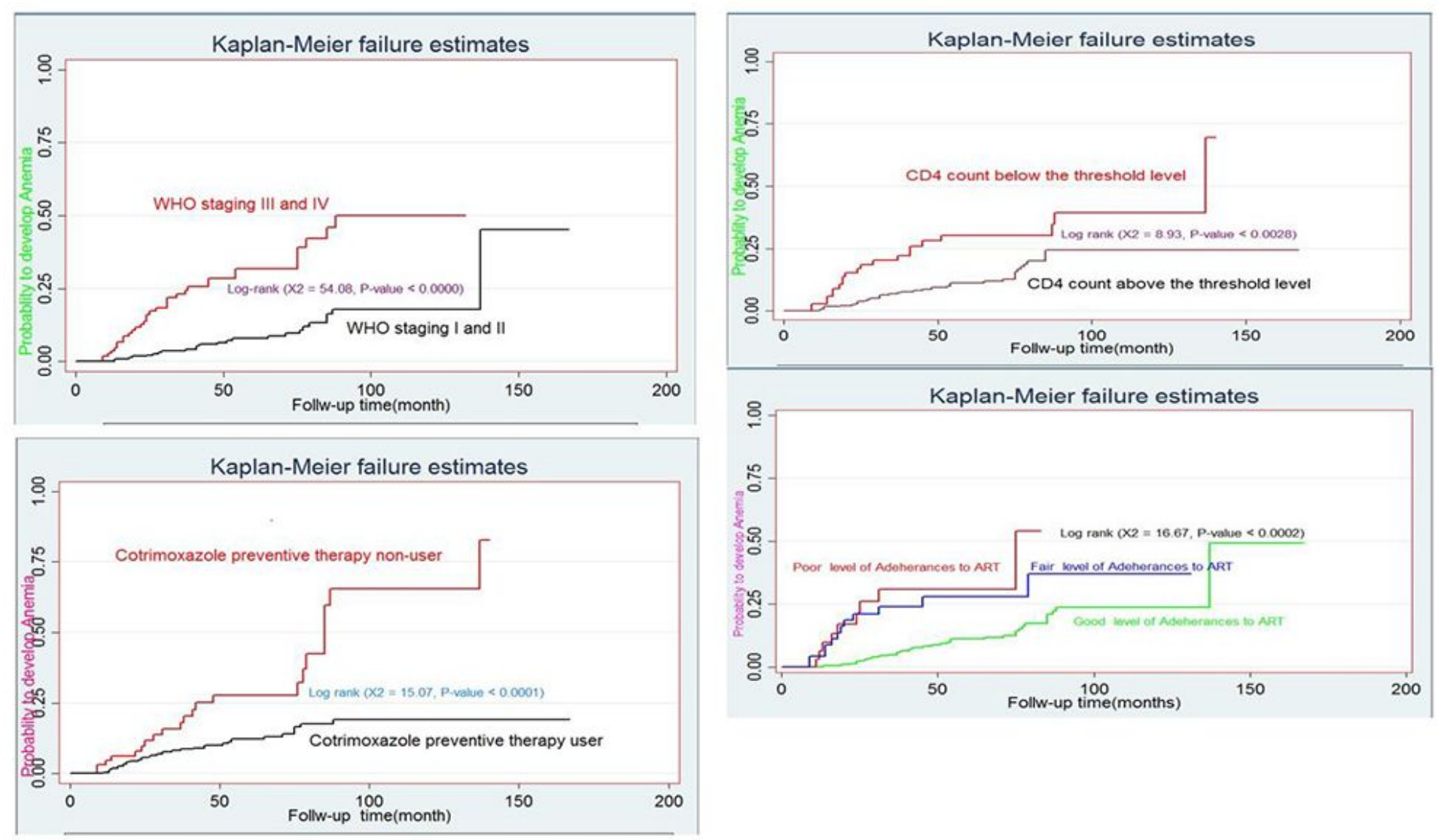

Figure 3

Kaplan-Meier failure estimate of anemia of the main predictor variable among children received Antiretroviral Therapy at Debre Tabor Referral Hospital and University of Gonder Compressive Specialized Hospital, Northwest, Ethiopia 2020 $(n=357)$ (continued): Kaplan-Meier failure estimate of anemia of the main predictor variable among children received Antiretroviral Therapy at Debre Tabor Referral Hospital and University of Gonder Compressive Specialized Hospital, Northwest, Ethiopia $2020(n=357)$ 


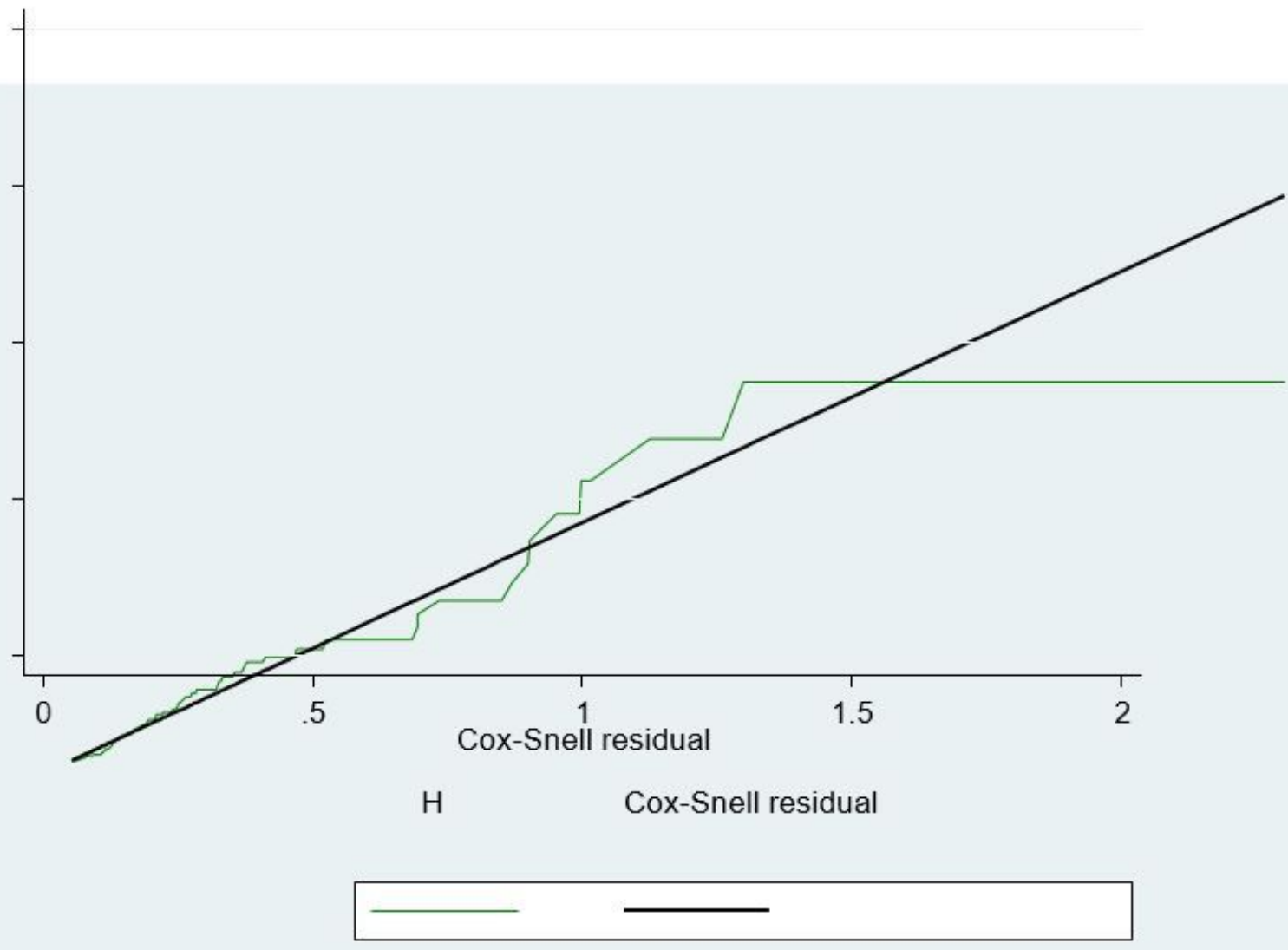

\section{Figure 4}

Cox-Snell residual Nelson- Alen cumulative hazard graph for the goodness of model fitness which shows the hazard function follows the 450 closeness among children received Antiretroviral Therapy at Debre Tabor Referral Hospital and University of Gonder Compressive Specialized Hospital, Northwest, Ethiopia 2020 ( $n=357)$. 